\title{
ANALISIS RISIKO KECELAKAAN KERJA PADA STASIUN KLARIFIKASI DENGAN METODE ANALYTIC HIERARCHY PROCESS (AHP) PT MOPOLI RAYA
}

\author{
Buchari $^{1}$, Mutia Irani ${ }^{2}$ \\ Departemen Teknik Industri, Fakultas Teknik, Universitas Sumatera Utara \\ Jl. Almamater Kampus USU, Medan 20155 \\ Email: ibossanti@yahoo.com, mutiairani1997@gmail.com
}

\begin{abstract}
ABSTRAK
Permasalahan yang dihadapi oleh PT Mopoli Raya adalah dari data dan observasi lapangan kasus kecelakaan pada stasiun klarifikasi yang paling besar terjadi pada tahun 2017 di mana terdapat enam kasus kecelakaan kerja. Tujuan dilakukannya penelitian ini adalah mengidentifikasi risiko kecelakaan kerja pada stasiun klarifikasi PT Mopoli Raya yang menyebabkan besarnya angka kecelakaan kerja. Metode yang digunakan dalam penelitian ini untuk menentukan faktor penyebab kecelakaan kerja paling berpengaruh yaitu menggunakan Analytic Hierachy Process (AHP) kemudian dilakukan pengendalian risiko keecelakaan kerja. Berdasarkan hasil perhitungan AHP, pengukuran faktor kecelakaan kerja yang memiliki total bobot tertinggi yaitu faktor manusia dengan bobot 0,2143, urutan kedua yaitu faktor peralalatan dengan bobot 0,2081, urutan ketiga yaitu faktor lingkungan dengan bobot 0,1960, urutan keempat yaitu peraturan perusahaan dengan bobot 0,1914, urutan kelima yaitu Standard Operating Procedure (SOP) dengan bobot 0,1901. Setelah itu, dilakukan analisis pengendalian risiko terhadap faktor manusia yang memilki bobot tertinggi sebagai faktor yang paling berpengaruh terhadap angka kecelakaan kerja, rekomendasi perbaikan yang dapat diberikan untuk mengendalikan tingkat kecelakaan kerja yang disebabkan oleh faktor manusia yaitu membuat peraturan yang mewajibkan pengguanaan APD yang menyesuaikan pada penyakit akbiat kerja yang sesuai potensi bahaya, membuat worksheet sebagai bahan inspeksi manajemen, membuat visual display pengunaan APD, membuat jadwal pelatihan K3 tentang pengunaan APD, manajemen melakukan pemeriksaan kesehatan pekerja secara prakarya dan berkala, perusahaan menyediakan fasilitas kesehatan untuk pekerja yang dilengkapi dengan dokter spesialis okupasi, membuat SOP disiplin sikap dalam bekerja, dan melakukan sosialisasi SOP disiplin sikap dalam bekerja.
\end{abstract}

Kata kunci: Pengendalian risiko kecalakaan kerja, analytic hierachy process (AHP)

\begin{abstract}
The problems are shown by PT Mopoli Raya is from the data Accident cases at the clarification station that occurred in 2017 where there were 6 cases of work accidents. The purpose of conducting this research is to find accurate information the method used in this study is to determine the factors that cause accidents, namely using the Analytic hierarchy process (AHP) and then transferring work accident tasks. Based on the results of the AHP calculation, the factors used are the highest total weight, namely the human factor with a weight of 0.2143, the second-order is the factor with a weight of 0.2081, the measurement of environmental factors with a weight of 0.1960, the main order is the company regulation with a weight of 0.1914, number five namely Standard Operating Procedure (SOP) with a weight of 0.1901. After that, an analysis of the factors that have the highest weight as the most influential factor on the accident rate, which can be given to control the level caused by human factors that form regulations that require the use of PPE regulating the disease due to work that is suitable for potential hazards, making worksheets as a management inspection material, making a visual display of the use of PPE, making OSH schedule training on the use of PPE, the management carries out a professional health check, the company provides health facilities for workers who are equipped with occupational specialists, makes SOP disciplined in working, and SOP socialization attitude attitude in working.
\end{abstract}

Keywords: Workplace risk management control, analytic hierachy process (AHP).

\section{Pendahuluan}

Keselamatan dan kesehatan kerja (K3) pada suatu perusahaan sangat penting dan menguhapuskan keselamatan dan kesehatan kerja (K3) pada perusaahaan tidak dapat ditoleransi. Banyak kecelakaan industri terjadi karena 
kelalaian faktor risiko pada kesemataan dan kesehatan pekerja dan penduduk di dekatnya. Kurangnya evaluasi pada sistem keselamatan dan kesehatan kerja pada suatu perusahaan menghasilkan akibat yang buruk yang dapat berakhir dengan mengancam keberadaan perusahaan [1].

Risiko terjadinya kecelakaan kerja menjadi perhatian utama di perusahaan. Hal ini disebabkan oleh akibatakibat yang terjadi pada kecelakaan kerja hingga konsekuensi yang mematikan dari kecelakaan ini. Hal tersebut menjadikan analisis risiko semakin penting. Keselamatan dan kesehatan kerja juga menjadi perhatian utama di seluruh dunia karena fakta bahwa risiko pekerjaan merupakan sumber utama bahaya. Mengambil tindakan pencegahan terhadap risiko dan bahaya di tempat kerja adalah salah satu tugas dasar dan tanggung jawab dalam manajemen kesehatan dan keselamatan kerja. Upaya untuk memberikan keselamatan di tempat kerja tidak hanya signifikan bagi kesehatan pekerja tetapi juga kegiatan manajerial yang tak terelakkan untuk kinerja ekonomi dan keuangan, produktivitas fasilitas dan kualitas serta stabilitas produksi [2].

Kecelakaan yang disebabkan oleh tindakan perbuatan manusia yang tidak memenuhi keselamatan disebut dengan unsafe human action seperti tidak memakai alat pelindung diri (APD), bekerja tidak sesuai prosedur, bekerja sambil bergurau, meletakkan barang atau alat kerja tidak benar, sikap kerja yang tidak selamat, bekerja di dekat alat yang bergerak atau berputar, kelelahan, kebosanan, dan lain-lain. Sedangkan kecelakaan yang disebabkan oleh keadaan lingkungan yang tidak aman disebut unsafe condition seperti mesin tanpa pengaman dan tetap menggunakan peralatan yang sudah tidak sempurna. Penerangan atau pencahayaan di dalam ruangan kurang memadai, ventilasi yang tidak baik, tata ruang yang tidak baik, lantai yang licin, dan lain-lain [3].

Menurut laporan terbaru Organisasi Perburuhan Internasional (ILO) bertajuk "Safety in Numbers", sekitar dua juta orang kehilangan nyawa mereka setiap tahun akibat kecelakaan, luka-luka, atau penyakit di tempat kerja. Angka tersebut setara dengan 5.000 pekerja per hari atau tiga orang setiap menitnya dari sekitar 270 juta kecelakaan kerja yang terjadi, 335 ribu di antaranya merupakan kecelakaan fatal, dan 160 juta penyakit akibat pekerjaan terjadi setiap tahun. Berdasarkan data Depnakertrans, angka kecelakaan kerja di Indonesia terkhusus industri kelapa sawit masih tergolong tinggi dengan jumlah 37.845 jumlah kasus kecelakaan kerja, meskipun cenderung turun dari tahun ke tahun [4].

Penelitian ini dilakukan di PT Mopoli Raya, yang merupakan perusahaan swasta yang bergerak dalam bidang perkebunan dan pengolahan hasil perkebunan kelapa sawit dengan hasil produk Minyak Sawit (CPO) dan Inti Sawit (Kernel). Tabel 1 menunjukkan rekapitulasi kecalakaan kerja yang terjadi di PT Mopoli Raya selama lima tahun terakhir.

Pada Tabel 1 dapat dilihat angka kecelakaan kerja dari tahun 2013 sampai dengan tahun 2015 menurun namun terjadi peningkatan pada tahun 2016 sampai dengan 2017. Stasiun klarifikasi merupakan stasiun yang paling rentan terjadinya kecelakaan kerja dengan jumlah kecelakaan sebanyak 14 kasus kecelakaan kerja dalam kurun waktu 2013 sampai dengan 2017. Adapun Tabel 2 menunjukkan rekapitulasi kecelakaan kerja pada stasiun klarifikasi tahun 2017.

Oleh karena itu perlu dilakukan identifikasi risiko kecelakaan kerja pada stasiun klarifikasi yang bertujuan untuk menentukan faktor-faktor penyebab terjadinya hal tersebut sehingga angka kecelakan kerja di stasiun klarifikasi PT Mopoli Raya dapat dikurangi. Metode yang digunakan yaitu menggunakan metode analytic hierarchy process (AHP).

Tabel 1. Rekapitulasi kecelakaan kerja PT Mopoli Raya tahun 2013-2017

\begin{tabular}{lrrrrrr}
\hline \multicolumn{1}{c}{ Nama Stasiun } & 2013 & 2014 & 2015 & 2016 & 2017 & Total \\
\hline Loading Ramp & 1 & 1 & 1 & - & - & 3 \\
Sterilizer & 1 & 2 & 1 & - & - & 4 \\
Thresser & - & 1 & - & 1 & 2 & 4 \\
Press & 2 & - & 1 & 2 & - & 5 \\
Klarifikasi & 2 & 1 & 2 & 3 & 6 & 14 \\
\hline Total & 6 & 5 & 5 & 6 & 8 & 30 \\
\hline
\end{tabular}

Tabel 2. Rekapitulasi kecelakaan kerja pada stasiun klarifikasi tahun 2017

\begin{tabular}{lrrl}
\hline \multicolumn{1}{c}{ Jenis Kecalakaan Kerja } & Frekuensi & Jumlah Korban (Orang) & Waktu \\
\hline Tergelincir sewaktu membersihkan serabut & 1 & 1 & Maret \\
Terkena semburan air pengencer minyak & 1 & 1 & Mei \\
Terpleset di kolam fat-pit & 1 & 1 & September \\
Terkena air panas & 2 & 2 & Oktober \\
Jatuh dari ketinggian & 1 & 1 Oktober \\
\hline
\end{tabular}




\section{Metode Penelitian}

Jenis penelitian yang digunakan adalah descriptive research yaitu penelitian yang melakukan pemecahan terhadap suatu masalah yang ada secara sistematik, faktual, dan akurat berdasarkan fakta yang ada. Penelitian dilaksanakan di PT Mopoli Raya. Pabrik kelapa sawit PT Mopoli Raya terletak di desa Gedong Biara Kecamatan Seruway, Kabupaten Aceh Timur, Provinsi Nanggroe Aceh Darussalam. Waktu penelitian dilakukan pada bulan Juli hingga September 2018. Objek penelitian yang diamati adalah stasiun klarifikasi pada PT Mopoli Raya dikarenakan tingginya angka kecelakaan kerja yang terjadi pada stasiun klarifikasi PT Mopoli Raya. Variabel penelitian terbagi menjadi dua yaitu variabel independen dan variabel dependen. Variabel independen adalah variabel yang mempengaruhi variabel dependen baik secara positif maupun negatif, sedangkan variabel dependen merupakan variabel yang nilai dipengaruhi atau ditentukan oleh nilai variablel lain [5]. Variabel independen memengaruhi variabel dependen baik secara positif maupun negatif, variabel independen pada penelitian ini adalah faktor manusia, faktor peralatan, faktor lingkungan, SOP, dan peraturan perusahaan. Variabel dependen dalam penelitian ini adalah menurunnya angka kecelakaan kerja. Kerangka konseptual dari penelitian ini dapat dilihat pada Gambar 1.

\section{Metode Pengumpulan Data}

Data yang diambil terbagi menjadi dua yaitu data primer dan data sekunder. Data primer adalah informasi atau data orisinil yang dikumpulkan dan berhubungan dengan objek yang akan diteliti. Data primer yang digunakan dalam penelitian ini mengenai jenis kecelakaan kerja dan sistem manajemen K3, yang diperoleh dengan metode penyebaran kuisioner AHP dan wawancara. Data sekunder adalah data yang diperoleh secara tidak langsung yang biasanya berbentuk dokumen, file, arsip, atau catatan-catatan perusahaan. Data ini diperoleh melalui dokumentasi perusahaan, dan literatur yang berhubungan dengan penelitian

\section{Metode Pengolahan Data}

1. Identifikasi Faktor Penyebab

2. Penyusunan Hirarki

Suatu tujuan yang bersifat umum dapat dapat dijabarkan dalam beberapa sub tujuan yang lebih terperinci yang dapat menjelaskan apa yang dimaksud dalam tujuan pertama. Penjabarannya dapat dilakukan terus hingga akhirnya diperoleh tujuan yang bersifat operasional. Dan pada hirarki terendah inilah dilakukan proses evaluasi atas alternatif-alternatif, yang merupakan ukuran dari pencapaian tujuan utama dan pada hirarki terendah ini dapat ditetapkan dalam satuan apa kriteria diukur [8].

3. Penentuan Prioritas

Pada tahapan ini, seluruh kriteria yang berada pada setiap tingkat hirarki diberikan penilaian kepentingan relatif antara satu kriteria dengan kriteria lainnya. Penilaian tersebut menggunakan standar pembobotan Saaty dengan skala berkisar dari 1 hingga 9 dan kebalikannya. Keterangan mengenai skala tersebut dapat dilihat pada Tabel 3 [9].

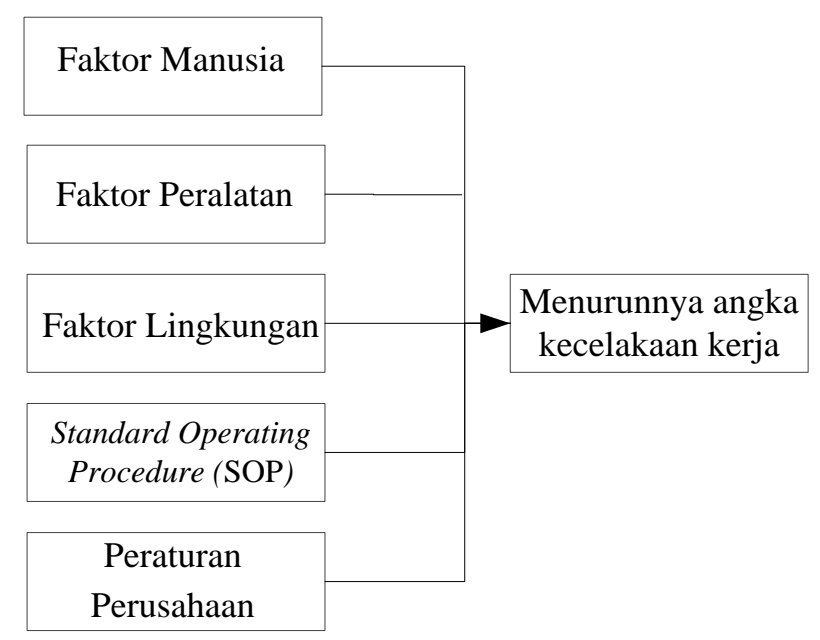

Gambar 1. Kerangka konseptual penelitian 


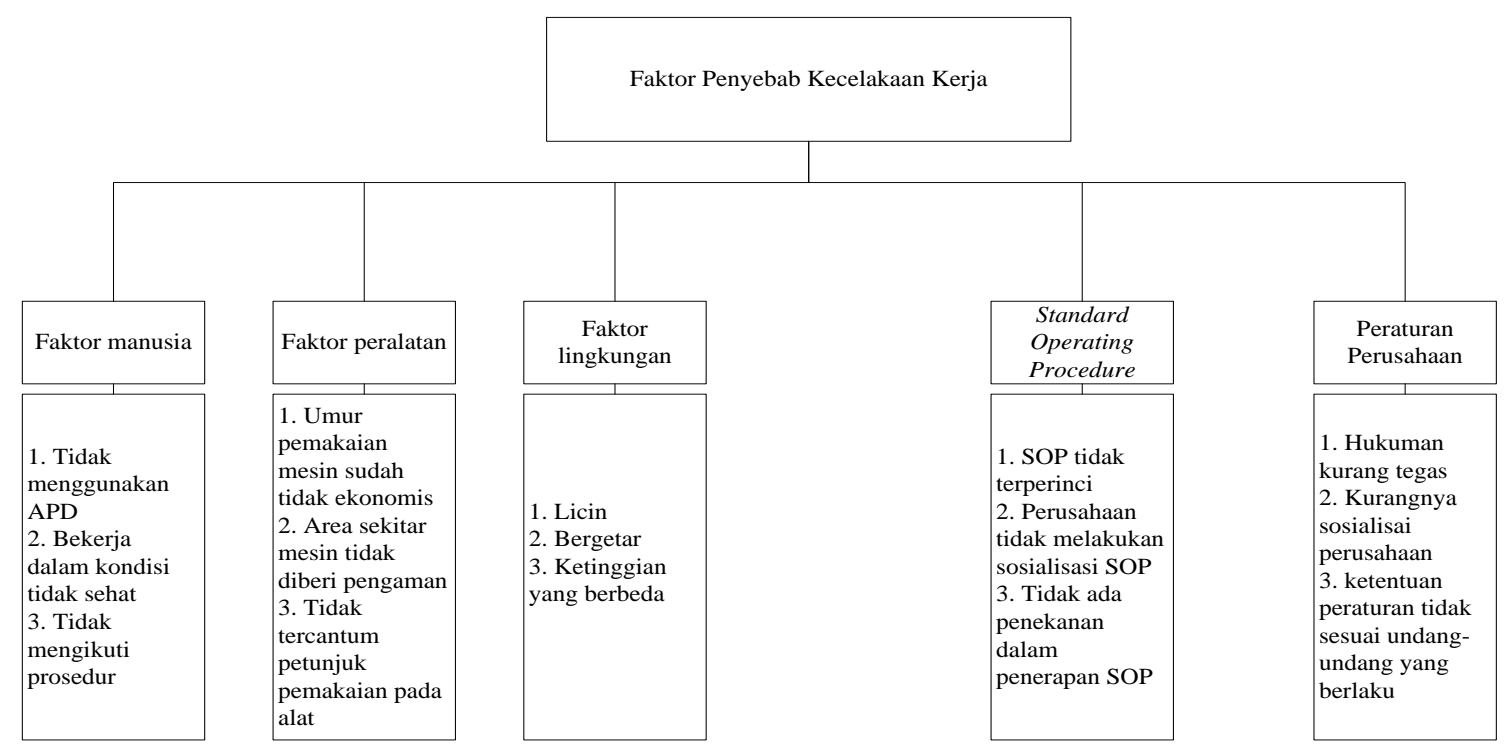

Gambar 2. Hierarki pemilihan faktor kecelakaan kerja

Tabel 3. Penilaian kepentingan relatif kriteria menggunakan skala Saaty

\begin{tabular}{cl}
\hline Skala & \multicolumn{1}{c}{ Keterangan } \\
\hline 1 & Kedua elemen sama penting \\
3 & Emelen yang satu sedikit lebih penting dibanding yang lainnya \\
5 & Elemen yang satu esensial atau sangat penting dibanding elemen lainnya \\
7 & Satu elemen jelas lebih penting dari elemen yang lainnya \\
9 & Satu elemen mutlak lebih penting \\
$2,4,6,8$ & Nilai-nilai kompromi diantara dua pertimbangan yang berdektan \\
\hline
\end{tabular}

4. Konsistensi

Saaty's AHP juga memberikan pertimbangan terhadap pertanyaan mengenai logika konsistensi dari evaluator. Indeks konsistensi (CI) adalah perhitungan matematis untuk setiap perbandingan berpasangan matrik perbandingan. CI ini menyatakan deviasi konsistensi. Kemudian indeks acak (Random index/RI), sebagai hasil dari respon acak yang mutlak dibagi dengan CI dihasilkan rasio konsistensi (CRs). Semakin tinggi CRs maka semakin rendah konsistensi, demikian juga sebaliknya[10].

5. Memberikan rekomendasi pengendalian risiko kecelakaan kerja

\section{Hasil dan Pembahasan}

Faktor penyebab kecelakaan kerja pada PT Mopoli Raya adalah faktor manusia, faktor peralatan, faktor lingkungan, Standard Operational Procedure (SOP), dan Peraturan Perusahaan. Hierarki dari faktor penyebab kecelakaan kerja dapat dilihat pada Gambar 2.

Berdasarkan hasil pengolahan faktor kecelakaan kerja yang memiliki total bobot tertinggi yaitu faktor manusia dengan bobot 0,2143 , urutan kedua yaitu faktor peralalatan dengan bobot 0,2081 , urutan ketiga yaitu faktor lingkungan dengan bobot 0,1960 , urutan keempat yaitu peraturan perusahaan dengan bobot 0,1914 , urutan kelima yaitu Standard Operating Procedure (SOP) dengan bobot 0,1901. Pada faktor manusia penyebab kecelakaan kerja paling terbesar bobotnya yaitu dikarekan operator yang bekerja pada tiap stasiun tidak mengikuti prosedur kerja yang diberikan oleh perusahaan. Tabel 4 menunjukkan rekapitulasi bobot parsial setiap level.

Perancangan rekomendasi atau usulan perbaikan dilakukan berdasarkan risiko kecelakaan kerja yang terjadi. Dengan adanya usulan perbaikan yang diberikan nantinya perusahaan dapat mengurangi tingkat kecelakaan dan mencegah adanya kecelakaan yang serupa lagi dengan sebelumnya. Tabel 5 menunjukkan analisis kejadian dari sumber bahaya dan usulan perbaikan yang diberikan. 
Tabel 4. Rekapitulasi bobot parsial setiap level

\begin{tabular}{|c|c|c|c|c|c|}
\hline Atribut & Level 2 & Rangking & Atribut & Level 3 & Rangking \\
\hline \multirow{3}{*}{$\begin{array}{l}\text { Faktor } \\
\text { Manusia }\end{array}$} & \multirow{3}{*}{0,2143} & \multirow{3}{*}{1} & Tidak menggunakan APD & 0,3547 & 3 \\
\hline & & & Bekerja dalam kondisi tidak sehat & 0,2819 & 2 \\
\hline & & & Tidak mengikuti prosedur & 0,3634 & 1 \\
\hline \multirow{3}{*}{$\begin{array}{l}\text { Faktor } \\
\text { Peralatan }\end{array}$} & \multirow{3}{*}{0,2081} & \multirow{3}{*}{2} & Umur pemakaian mesin sudah tidak ekonomis & 0,3850 & 2 \\
\hline & & & Area sekitar mesin tidak diberi pengaman & 0,2250 & 3 \\
\hline & & & Tidak tercantum petunjuk pemakaian pada alat & 0,3901 & 1 \\
\hline \multirow{3}{*}{$\begin{array}{c}\text { Faktor } \\
\text { Lingkungan }\end{array}$} & \multirow{3}{*}{0,1960} & \multirow{3}{*}{3} & Licin & 0,3844 & 1 \\
\hline & & & Bergetar & 0,3196 & 2 \\
\hline & & & Ketinggian yang berbeda & 0,2960 & 3 \\
\hline \multirow{3}{*}{ SOP } & \multirow{3}{*}{0,1901} & \multirow{3}{*}{5} & SOP tidak terperinci & 0,3339 & 2 \\
\hline & & & Perusahaan tidak melakukan sosialisasi SOP & 0,3354 & 1 \\
\hline & & & Tidak ada penekanan dalam penerapan SOP & 0,3307 & 3 \\
\hline \multirow{3}{*}{$\begin{array}{l}\text { Peraturan } \\
\text { Perusahaan }\end{array}$} & \multirow{3}{*}{0,1914} & \multirow{3}{*}{4} & Hukuman kurang tegas & 0,4115 & 1 \\
\hline & & & Kurangnya Sosialiasi Peraturan Perusahaan & 0,2625 & 3 \\
\hline & & & Peraturan tidak sesuai dengan UU yang berlaku & 0,3260 & 2 \\
\hline
\end{tabular}

\section{Kesimpulan}

Terdapat 5 kriteria sebagai ketentuan dalam pemilihan faktor penyebab kecelakaan kerja yang paling berpengaruh yaitu, faktor manusia, faktor peralatan, faktor lingkungan, standard operating procedure, peraturan perusahaan. Berdasarkan hasil pengolahan faktor kecelakaan kerja yang memiliki total bobot tertinggi yaitu faktor manusia dengan bobot 0,2143 , urutan kedua yaitu faktor peralalatan dengan bobot 0,2081 , urutan ketiga yaitu faktor lingkungan dengan bobot 0,1960, urutan keempat yaitu peraturan perusahaan dengan bobot 0,1914 , urutan kelima yaitu SOP dengan bobot 0,1901 . Faktor kecelakaan kerja yang memiliki total bobot tertinggi yaitu faktor manusia. Rekomendasi perbaikan yang dapat diberikan untuk mengendalikan tingkat kecelakaan kerja yang disebabkan oleh faktor manusia yaitu membuat peraturan yang mewjibkan pengguanaan APD yang menyesuaikan pada penyakit akbiat kerja yang sesuai potensi bahaya, membuat worksheet sebagai bahan inspeksi manajemen, membuat visual display pengunaan APD, membuat jadwal pelatihan K3 tentang pengunaan APD, manajemen melakukan pemeriksaan kesehatan pekerja secara prakarya dan berkala, perusahaan menyediakan fasilitas kesehatan untuk pekerja yang dilengkapi dengan dokter spesialis okupasi, membuat SOP disiplin sikap dalam bekerja, dan melakukan sosialisasi SOP disiplin sikap dalam bekerja.

\section{Referensi}

[1] A. Badri, S. Nadeau, \& A. Gbodossou, "Proposal of a risk-factor-based analytic approach for integrating occuptional health and safety into project risk evaluation," Accident Analysis \& Prevention, vol. 48, hal. 223-234, Sep 2012.

[2] D. Majumber, J. Debnath, \& A. Biswas, "Risk analysis in construction sites using fuzzy reasoning and fuzzy analytic hierarchy process," Procedia Technology, vo. 10, hal. 604-614, 2013.

[3] F. Mallaping \& I. A. Samosir, Analisis potensi bahaya dan pengendaliannya (Studi kasus: indsutri kelapa sawit PT Manakara Unggul Lestari pada stasiun digester dan presser, clarifier, nut, dan kernel, Mamuju, Sulawesi Barat). Makassar: Fakultas Ilmu Kesehatan Universitas Islam Negeri Alauddin, 2014.

[4] R. A. Hadiguna, E. Wirdianto, \& A. Hasan, Penerapan analytic hierarchy process dalam perencanaan program keselamatan kerja (Studi kasus di Departemen Tambang PT Semen Padang). Padang: Universitas Andalas, 2010.

[5] S. Sinulingga, Metode penelitian. Medan: USU Press, 2013.

[6] E. Maharu, "Sistem pemeliharaan aset berbasis android untuk bangunan gedung (Studi kasus evaluasi Gedung V Fakultas Teknik Universitas Sebelas Maret Surakarta)," Universitas Sebelas Maret, 2016, tidak dipublikasikan.

[7] K. Makkasau, Pengunaan metode Analytic Hierachy Process (AHP) dalam penentuan prioritas program kesehatan (Studi kasus program promosi kesehatan). Maluku: Dinas Kesehatan Kota Ternate, 2010.

[8] M. Yusuf, Peran keselamatan dan kesehatan kerja dengan pendekatan analytical hierarchy process dan ergonomi. Yogyakarta: Institut Sains \& Teknologi AKPRIND, 2018.

[9] F. R. Sari \& D. Indra, Penerapan metode analytic hierarchy process dalam sistem penunjang keputusan untuk pemilihan asuransi. Depok: Universitas Indonesia, 2018.

[10] K. Teknomo, H. Siswanto, \& S. A. Yudhanto, "Pengunaan metode analytic hierarchy process dalam menganalisa faktor-faktor yang mempengaruhi pemilihan moda ke kampus," Dimensi Teknik Sipil, vol. 1, no. 1, hal. 31-40. 
Tabel 5. Rekomendasi perbaikan untuk mengurangi risiko kecelakaan kerja PT Mopoli Raya

\begin{tabular}{|c|c|c|}
\hline Faktor & $\begin{array}{l}\text { Risiko Kecelakaan } \\
\text { Kerja }\end{array}$ & Rekomendasi Perbaikan \\
\hline \multirow{4}{*}{$\begin{array}{l}\text { Faktor } \\
\text { Manusia }\end{array}$} & $\begin{array}{l}\text { Tidak menggunakan } \\
\text { APD }\end{array}$ & $\begin{array}{l}\text { 1. Membuat peraturan yang mewajibkan penggunaan APD yang sesuai } \\
\text { dengan potensi bahaya dan potensi timbulnya penyakit akibat. } \\
\text { 2. Membuat worksheet penggunaan APD sebagai bahan inspeksi tim } \\
\text { HSE untuk para pekerja. } \\
\text { 3. Membuat visual display mengenai penggunaan APD } \\
\text { 4. Membuat jadwal pelatihan K } 3 \text { tentang manfaat dan cara penggunaan } \\
\text { APD yang wajib dihadiri seluruh pekerja PT Mopoli Raya }\end{array}$ \\
\hline & & \\
\hline & $\begin{array}{l}\text { Bekerja dalam kondisi } \\
\text { tidak sehat }\end{array}$ & $\begin{array}{l}\text { 1. Manajemen diharapkan melakukan pemeriksaan kesehatan pekerja } \\
\text { prakarya (bagi karyawan baru) dan berkala (bagi karyawan lama) } \\
\text { secara rutin } \\
\text { 2. PT Mopoli Raya menyediakan fasilitas kesehatan untuk para pekerja } \\
\text { yang dilengkapi dengan dokter yang memilki keahlian dalam } \\
\text { menganalisis penyakit akibat kerja. }\end{array}$ \\
\hline & $\begin{array}{l}\text { Tidak mengikuti } \\
\text { prosedur }\end{array}$ & $\begin{array}{l}\text { 1. Pembuatan SOP disiplin sikap dalam bekerja } \\
\text { 2. Melakukan sosialisasi SOP disiplin sikap dalam bekerja }\end{array}$ \\
\hline \multirow{3}{*}{$\begin{array}{l}\text { Faktor } \\
\text { Peralatan }\end{array}$} & $\begin{array}{l}\text { Umur pemakaian mesin } \\
\text { sudah tidak ekonomis }\end{array}$ & $\begin{array}{l}\text { 1. Melakukan maintenance secara berkala } \\
\text { 2. Mengganti mesin dengan mesin yang terbaru sehingga tidak terjadi } \\
\text { kerusakan mesin. }\end{array}$ \\
\hline & $\begin{array}{c}\text { Area sekitar mesin } \\
\text { tidak diberi pengaman }\end{array}$ & $\begin{array}{l}\text { 1. Melakukan pemasangan safety guard pada daerah mesin-mesin yang } \\
\text { merupakan sumber bahaya }\end{array}$ \\
\hline & $\begin{array}{l}\text { Tidak tercantum } \\
\text { petunjuk pemakaian } \\
\text { pada alat }\end{array}$ & $\begin{array}{l}\text { 1. Membuat visual display mengenai penggunaan alat dan membuat } \\
\text { SOP penggunaan alat }\end{array}$ \\
\hline \multirow{3}{*}{$\begin{array}{l}\text { Faktor } \\
\text { Lingkung } \\
\quad \text { an }\end{array}$} & Licin & 1. Manajemen melakukan perbaikan menggunakan metode $5 \mathrm{~S}$ \\
\hline & Bergetar & 1. Memasang peredam getaran \\
\hline & $\begin{array}{l}\text { Ketinggian yang } \\
\text { berbeda }\end{array}$ & 1. Memasang safety sign \\
\hline \multirow{3}{*}{ SOP } & SOP tidak terperinci & 1. Manajemen membuat SOP terbaru yang lebih terperinci. \\
\hline & $\begin{array}{l}\text { Perusahaan tidak } \\
\text { melakukan sosialisasi } \\
\text { SOP }\end{array}$ & $\begin{array}{l}\text { 1. Manajemen melakukan sosialisasi SOP dan mewajibkan semua } \\
\text { pekerja untuk hadir pada sosialisasi. Bagi para pekerja yang tidak } \\
\text { mengikuti SOP akan dikenakan sanksi. Bentuk dari sanksi yang akan } \\
\text { dijatuhkan sesuai dengan kebijakan perusahaan }\end{array}$ \\
\hline & $\begin{array}{l}\text { Tidak ada penekanan } \\
\text { dalam penerapan SOP }\end{array}$ & 1. Perusahaan membuat sanksibagi pekerja yang tidak mengikuti SOP. \\
\hline \multirow{3}{*}{$\begin{array}{l}\text { Peraturan } \\
\text { Perusaha } \\
\quad \text { an }\end{array}$} & Hukuman kurang tegas & $\begin{array}{l}\text { 1. Manajemen melakukan pengawasan dengan baik } \\
\text { 2. Manajemen memberikan sanksi kepada pekerja yang melanggar } \\
\text { SOP atau peraturan perusahaan }\end{array}$ \\
\hline & $\begin{array}{l}\text { Kurangnya sosialisasi } \\
\text { Peraturan Perusahaan }\end{array}$ & $\begin{array}{l}\text { 1. Membuat penjadwalan sosialisasi peraturan perusahaan maupun } \\
\text { SOP secara berkala }\end{array}$ \\
\hline & $\begin{array}{l}\text { Peraturan tidak sesuai } \\
\text { dengan undang undang } \\
\text { yang berlaku }\end{array}$ & $\begin{array}{l}\text { 1. Perusahaan menerapkan peraturan perundangan standarisasi kerja } \\
\text { yang sesuai }\end{array}$ \\
\hline
\end{tabular}

